\title{
Ice-shelf tidal flexure and subglacial pressure variations
}

\author{
Ryan T. Walker a,b,*, Byron R. Parizek ${ }^{\mathrm{c}}$, Richard B. Alley ${ }^{\mathrm{a}, \mathrm{b}}$, Sridhar Anandakrishnan ${ }^{\mathrm{a}, \mathrm{b}}$, \\ Kiya L. Riverman ${ }^{a}$, Knut Christianson ${ }^{\mathrm{d}}$ \\ ${ }^{a}$ Department of Geosciences, 408 Deike Building, Pennsylvania State University, University Park, PA 16802, USA \\ ${ }^{\mathrm{b}}$ Earth and Environmental Systems Institute, Pennsylvania State University, University Park, PA 16802, USA \\ ' Mathematics and Geoscience, 181 Smeal Building, Penn State DuBois, College Place, DuBois, PA 15801, USA \\ ${ }^{\mathrm{d}}$ Department of Physics, St. Olaf College, 1520 St. Olaf Avenue, Northfield, MN 55057, USA
}

\section{A R T I C L E I N F O}

\section{Article history:}

Received 13 July 2012

Received in revised form

1 November 2012

Accepted 2 November 2012

Editor: J. Lynch-Stieglitz

Available online 27 November 2012

\section{Keywords:}

ice shelf

tidal flexure

subglacial hydrology

\begin{abstract}
A B S T R A C T
We develop a model of an ice shelf-ice stream system as a viscoelastic beam partially supported by an elastic foundation. When bedrock near the grounding line acts as a fulcrum, leverage from the ice shelf dropping at low tide can cause significant $(\sim 1 \mathrm{~cm})$ uplift in the first few kilometers of grounded ice. This uplift and the corresponding depression at high tide lead to basal pressure variations of sufficient magnitude to influence subglacial hydrology. Tidal flexure may thus affect basal lubrication, sediment flow, and till strength, all of which are significant factors in ice-stream dynamics and grounding-line stability. Under certain circumstances, our results suggest the possibility of seawater being drawn into the subglacial water system. The presence of seawater beneath grounded ice would significantly change the radar reflectivity of the grounding zone and complicate the interpretation of grounded versus floating ice based on ice-penetrating radar observations.
\end{abstract}

(c) 2012 Elsevier B.V. All rights reserved.

\section{Introduction}

Ice sheets transition from grounded streams to floating shelves over a several-kilometer-wide grounding zone that extends between the landward limit of tidally induced flexure and the hydrostatic line at which ice begins to oscillate with the full tidal range (Fig. 1). Grounding zones are critical to ice-sheet dynamics, because processes here determine the mass flux from grounded to floating ice, and thus eventually to the ocean. Furthermore, the interactions of ice-stream basal hydrological processes with the tidally changing ocean may exert important influences on water pressure, sliding and sediment flux near the grounding zone. Early studies focused on providing fundamental data on position of the grounding line (i.e., the boundary between floating and grounded ice) and its motion in response to tidally induced flexure. Considerable success in this effort now motivates new studies examining the physical processes that take place at the ice-stream base in the grounding zone, and their effects on nearby subglacial hydrology.

Flexure of ice shelves due to ocean tides has been studied at least since Robin (1958), who observed the phenomenon on

\footnotetext{
${ }^{*}$ Corresponding author. Now at: Earth System Science Interdisciplinary Center, University of Maryland, College Park, MD 20742, USA and Cryospheric Sciences Laboratory, NASA Goddard Space Flight Center, Greenbelt, MD 20771, USA. Tel.: +13016146486.

E-mail address: ryan.t.walker@nasa.gov (R.T. Walker).
}

Maudheim Ice Shelf and noted that surface crevasses coincided with the location of maximum elastic stress. Holdsworth (1969) first modeled an ice shelf as an elastic beam, an approach followed in many subsequent studies (e.g., Holdsworth, 1977; Lingle et al., 1981; Smith, 1991; Vaughan, 1995); Schmeltz et al. (2002) extended the model to a two-dimensional elastic plate. Several studies of this type could not reconcile observations with a single value of the elastic (Young's) modulus for ice; Reeh et al. (2003) addressed this issue by adding viscoelastic behavior.

These studies have been concerned mainly with the floating ice shelf, and often directed towards determining the location of the grounding line, a goal shared by many remote-sensing studies. Recent observations (e.g., Fricker et al., 2009; Brunt et al., 2010, 2011; Bindschadler et al., 2011; Rignot et al., 2011) have used radar and laser altimetry to precisely map groundingline motion within grounding zones, building on earlier work by Scambos et al. (2007) with MODIS imagery. Sayag and Worster (2011) present interesting analytical and experimental results that help define the grounding-line position for an elastic ice shelf-ice sheet system at equilibrium, but do not yet include the effect of tides.

Another main goal of geophysical studies, both observational and model-based, has been to understand the widely varying effects of tidal cycles on ice-stream flow (Bindschadler et al., 2003; Anandakrishnan et al., 2003; Gudmundsson, 2007, 2011; Murray et al., 2007; Winberry et al., 2009, 2011; King et al., 2010; Walter et al., 2011). The tides clearly are forcing strong variations 


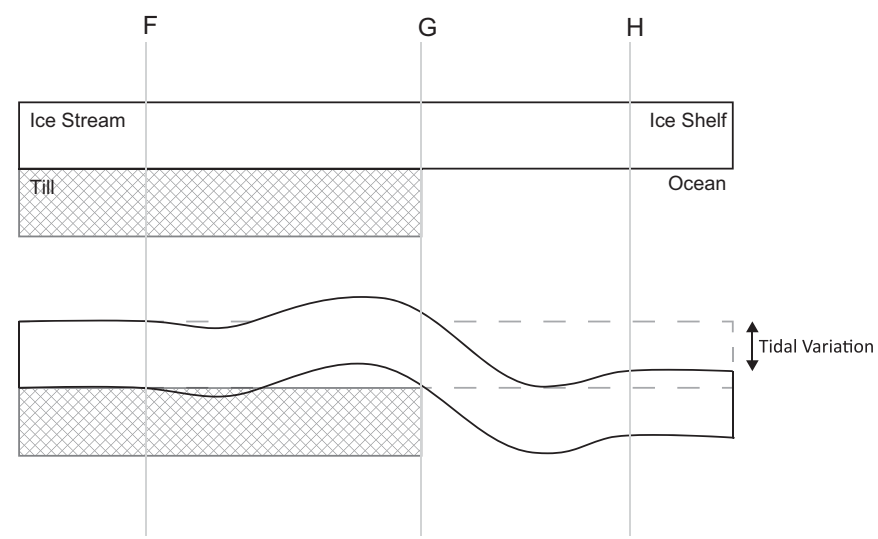

Fig. 1. Schematic of tidal flexure (not to scale). Inland limit of flexure denoted by $\mathrm{F}$, grounding line by G, and hydrostatic line by $\mathrm{H}$. Note that uplift inland of $\mathrm{G}$ is actually approximately $1 \%$ of the tidal height.

in horizontal velocity as well as causing vertical viscoelastic bending, pointing to the need for a fully coupled solution.

One important part of the path forward in developing such a solution comes from the tiltmeter studies of Smith (1991) and Jacobel and Bindschadler (1994), which show that significant bending can extend several $\mathrm{km}$ inland from the grounding line. Heinert and Riedel (2007) used a combination of GPS, gravimeters, and tiltmeters to observe an upward displacement of $1 \mathrm{~cm}$ approximately $1 \mathrm{~km}$ inland of the grounding line at Ekstroemisen at low tide, implying the existence of a fulcrum near the grounding line.

Studies addressing the ice-shelf flexural profile (e.g., Reeh et al., 2003) have achieved considerable accuracy using models in which the tributary ice stream is "clamped" with zero deformation at and inland of the grounding line, because the tidal changes of order $1 \mathrm{~m}$ are large compared to the observed inland changes of order $1 \mathrm{~cm}$ (Heinert and Riedel, 2007; Jacobel and Bindschadler, 1994; Smith, 1991). However, even the small inland uplift resulting from the leverage of the ice shelf as the tide falls could elastically transfer some of the weight of the ice, leading to a local drop in pressure beneath the ice stream. A sufficiently large pressure drop would affect icestream basal lubrication, till strength, and water exchange with the ocean, all of which are significant factors in grounding-line stability and ice-sheet mass balance. Thus, understanding the small tidal deflections inland of the grounding line seems to be a prerequisite for a fully coupled grounding-zone model. We therefore build on earlier work, but replace the clamp with a fulcrum at the grounding line (Fig. 1), to study this inland deformation. At this exploratory stage, we do not attempt the harder problem of allowing the grounding line to move. We note that the success of prior workers in quantitatively simulating the ice-shelf deformation assuming a clamped ice stream subject to the full tidal range indicates that grounding-line migration is small compared to the flexural wavelength of the ice shelf, likely because grounding lines tend to occupy relatively steep regions in basal topography (Anandakrishnan et al., 2007), supporting the use of a fixed fulcrum.

In the present study, we model tidal flexure of an ice shelf attached to an ice stream resting on an elastic foundation, with the goal of determining whether flexure-induced pressure variations at the ice-stream bed are sufficiently large to influence subglacial water flow.

\section{Model derivation}

Our model is a viscoelastic modification of Euler-Bernoulli elastic beam bending (e.g., Turcotte and Schubert, 2002). When a thin beam (of any rheology) is bent, the balance of vertical forces on a small element leads to the relation

$\partial_{x} V=-q$,

between the shear force $V$ on a vertical cross section and the applied load $q$. The bending moment $M$ is the integrated torque over a vertical cross-section of the beam:

$M=\int_{-0.5 h}^{0.5 h} \sigma_{x x} z d z$,

where $h$ is the beam thickness, $\sigma_{x x}$ is the longitudinal stress, and the vertical coordinate $z$ is zero on the beam centerline. The balance of torques then gives

$\partial_{x} M=V$,

which can be substituted into (1) to obtain

$\partial_{x}^{2} M=-q$.

To find the bending equation for a material, its rheology must be substituted into the definition (2) of the bending moment. The Maxwell viscoelastic material is the simplest rheology that displays both instantaneous elastic response and viscous damping. Reeh et al. (2003) argued that elastic-only models cannot capture all aspects of tidal flexure, while Gudmundsson (2011) demonstrated that the Maxwell model is sufficient to the purpose.

For bending of a thin beam, the Maxwell rheology for the horizontal direction (the along-flow direction of the shelf) is given by

$\dot{\sigma}_{x x}=\frac{E}{1-\lambda^{2}}\left(\dot{\epsilon}_{x x}-\frac{1}{2 v} \sigma_{x x}\right)$,

where $E$ is Young's modulus, $v$ is viscosity, $\epsilon_{x x}$ is longitudinal strain, $\lambda$ is Poisson's ratio, and dots indicate time derivatives. This may be derived from the equations for plane stress in a Maxwell material (Turcotte and Schubert, 2002) by assuming that the beam is thin in the vertical $(z)$ direction and that bending occurs only in the $x z$-plane. In the differential operator form used by Reeh et al. (2003), and following his assumption that advective terms in the total time derivative are negligible, the Maxwell rheology may be written as

$P\left(\sigma_{x x}\right) \equiv\left(\partial_{t}+\frac{E}{2 v\left(1-\lambda^{2}\right)}\right) \sigma_{x x}=\left(\frac{E}{1-\lambda^{2}} \partial_{t}\right) \epsilon_{x x} \equiv Q\left(\epsilon_{x x}\right)$.

Applying the operator $P$ to the bending moment $M$ results in a partial differential equation relating $M$ and the vertical displacement $w$ :

$\partial_{t} M+\frac{E}{2 v\left(1-\lambda^{2}\right)} M=-D \partial_{t} \partial_{x}^{2} w$,

where the flexural rigidity of the beam is defined as

$D \equiv \frac{E h^{3}}{12\left(1-\lambda^{2}\right)}$,

and we have used the curvature-based relation

$\epsilon_{x x}=-z \partial_{x}^{2} w$,

between strain and vertical displacement (e.g., Turcotte and Schubert, 2002).

Because we are interested in modeling flexure of the grounded ice as well as the ice shelf, we consider a partially supported beam. If the till underlying the ice stream is assumed to be elastic, the situation is analogous to a Winkler foundation in soil mechanics, and an extra term is added to (4):

$\partial_{x}^{2} M=k w-q$,

where the spring constant $k$ for compression is Young's modulus for the foundation divided by the thickness of the foundation (Jones, 1997). The applied load $q$ is nonzero only for the floating 
ice shelf, where it comes from the tide:

$q=\rho_{\text {sw }} g(a \sin \omega t-w)$,

where $a$ and $\omega$ are the tidal amplitude and frequency, and $\rho_{s w}$ is the density of seawater (Holdsworth, 1969).

Finally, if we make the simplifying assumption that the viscosity $v$ (but not the thickness $h$ or flexural rigidity $D$ ) is constant with respect to $x$, we can combine the two previous equations for the bending moment $M$ (taking $\partial_{x}^{2}$ of (7) and substituting (10)) to obtain

$\partial_{t}\left(k w+\partial_{x}^{2}\left(D \partial_{x}^{2} w\right)\right)+\frac{E k}{2 v\left(1-\lambda^{2}\right)} w=\partial_{t} q+\frac{E}{2 v\left(1-\lambda^{2}\right)} q$.

We note that in the limit $v \rightarrow \infty$ our viscoelastic bending equation reduces to the familiar equation for an elastic beam (e.g., Turcotte and Schubert, 2002):

$\frac{d^{2}}{d x^{2}}\left(D \frac{d^{2}}{d x^{2}} w\right)=q-k w$

The addition of viscous damping in our model affects the timing of the flexural response to the tide, while elastic behavior continues to dominate the solution. Our assumption of constant viscosity is thus reasonable for an exploratory model; c.f. the use of constant material parameters to successfully match observations by Reeh et al. (2003). Model sensitivities to choices of parameter values are considered later in the paper.

The equation is discretized and solved using Hermite cubic finite elements and fully implicit time differencing. Model resolution is $100 \mathrm{~m}$ in space and $600 \mathrm{~s}$ in time.

\section{Simulations}

\subsection{Control experiment}

The ice shelf-ice stream is $100 \mathrm{~km}$ long, with $50 \mathrm{~km}$ each of grounded and floating ice. The grounded ice has a uniform thickness of $1000 \mathrm{~m}$, while the ice shelf tapers to $300 \mathrm{~m}$ thick at the ice front following a nonlinear profile similar to that used by Holland et al. (2008):

$h=\frac{\alpha_{1}}{\left(\alpha_{2}+\left(x-\chi_{g l}\right)\right)^{1 / m}}$,

where constants $\alpha_{1}$ and $\alpha_{2}$ are chosen to give the desired thicknesses at the grounding line and ice front, and $x_{g l}$ is the position of the grounding line. We set $m=3$ to obtain a profile closer to that of a shelf with negligible lateral drag $(m=4)$ than to the linear profile $(m=-1)$ of a shelf in which lateral drag fully supports the driving stress. This relatively steep profile leads to a rapid decrease in rigidity (8), preventing the overestimate of leverage that would result from assuming an untapered shelf; some ice stream-ice shelf systems thus will have at least slightly more inland deflection than we calculate here.

We assume that the upstream end of the ice stream is simply supported $(w=0, M=0)$, while the vertical displacement at the ice front is given by the tide, and (consistent with observations) we impose $\partial_{x} w=0$ there. At the grounding line, we impose a fulcrum $(w=0)$, so that the shelf acts as an overhanging beam (e.g., Hibbeler, 2000). We assume an elastic foundation underlying the grounded ice, and test a wide range of spring constants to find those that are consistent with the $\sim 1 \mathrm{~cm}$ maximum deflection observed by Heinert and Riedel (2007). We then check whether the range of consistent spring constants matches the range expected for possible basal conditions such as subglacial till over bedrock, and find good agreement. The situation we model is somewhat simpler than that of Heinert and Riedel (2007), who inferred transient grounding and ungrounding of Ekstromeisen from a ridge downstream of the zero-tide grounding line, but for exploratory process modeling we do not believe that this should be a major issue.

We set Young's modulus and Poisson's ratio for ice to 4.8 GPa and 0.4, respectively, following Gudmundsson (2011), who showed that these values make the behavior of a Maxwell material essentially identical to that of the more complicated Burgers material used by Reeh et al. (2003). We find that a viscosity of $v=10^{15}$ Pa s allows for noticeable departure from purely elastic behavior while remaining high enough to prevent underdamping, consistent with observations. Model sensitivity to these and other parameters is discussed in the next section.

Results for the control experiment, which uses a diurnal tide varying between $\pm 1 \mathrm{~m}$ in height and a spring constant of $k=5 \times 10^{6} \mathrm{~Pa} \mathrm{~m}^{-1}$, are shown in Figs. 2 and 3. The grounded ice experiences a peak deflection of $\pm 10.3 \mathrm{~mm}$ at the node $600 \mathrm{~m}$ inland of the grounding line, consistent with the $1 \mathrm{~cm}$ uplift reported by Heinert and Riedel (2007). Deflections greater than

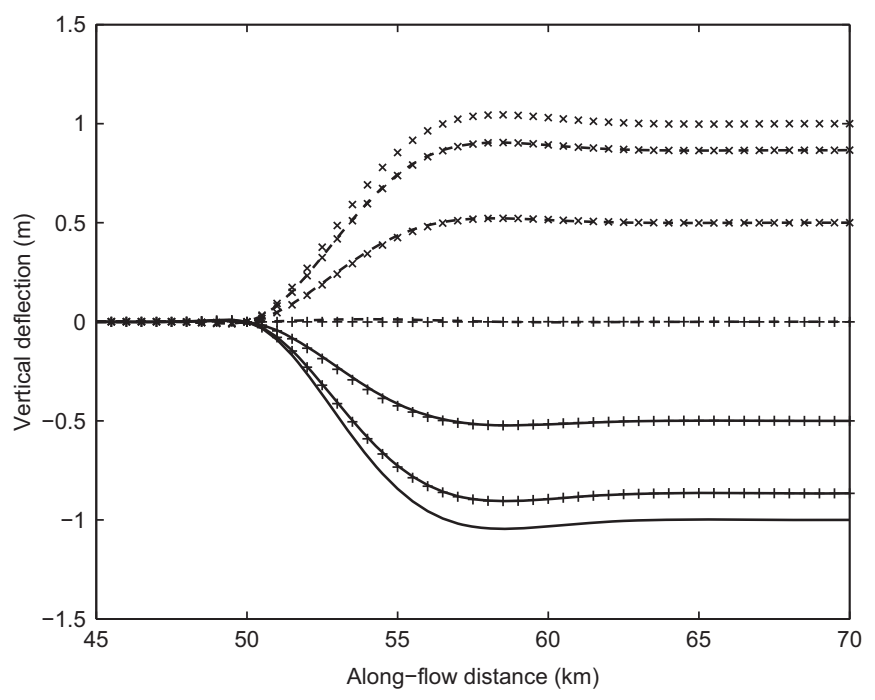

Fig. 2. Near-grounding line vertical deflection at 2-h intervals through one 24-h tidal cycle. Grounding line is at $x=50 \mathrm{~km}$. Rising tide (with positive height above datum) shown by $\times$, falling (positive) by dashed line, falling (negative) by solid line, and rising (negative) by + . Each solution remains constant for $x<45 \mathrm{~km}$ or $x>70 \mathrm{~km}$.

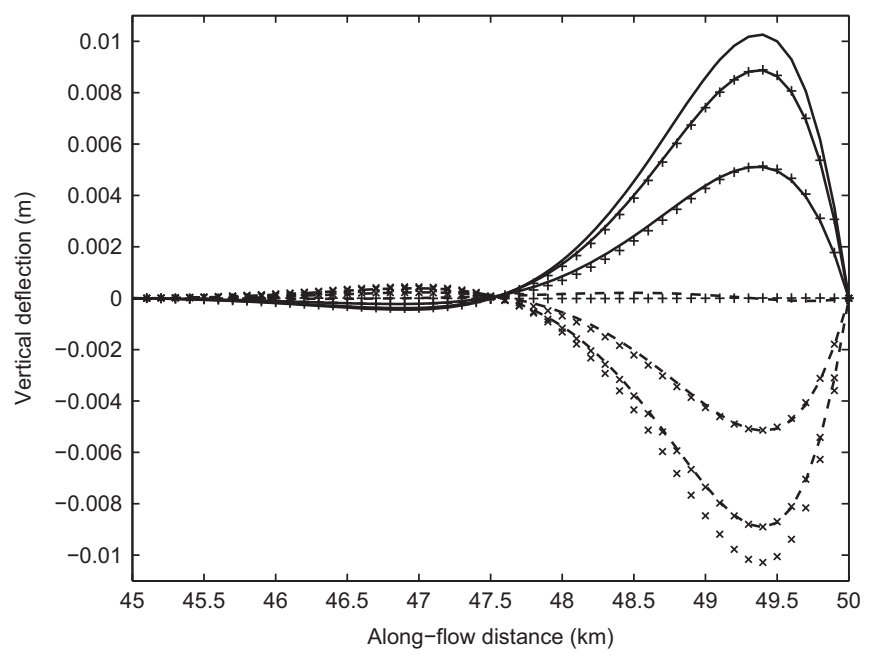

Fig. 3. Closeup of Fig. 2 showing vertical deflection for grounded ice only. Note that the slight offset between corresponding deflections for rising and falling tides is caused by viscous damping. 
$1 \mathrm{~mm}$ continue up to $2.1 \mathrm{~km}$ inland of the grounding line, and deflections greater than $0.1 \mathrm{~mm}$ up to $4.3 \mathrm{~km}$ inland.

On the ocean side, the majority of the shelf (at least the last $30 \mathrm{~km}$ ) remains very close to flotation, as expected. Deflections approximately $8 \mathrm{~km}$ offshore can exceed the tidal height by as much as $4.5 \mathrm{~cm}$ at high and low tide, a phenomenon observed in e.g., Reeh et al. (2003) which is similar to the formation of forebulges during flexure of lithospheric plates. At high tide, the deflection remains within $1 \mathrm{~cm}$ of the $1 \mathrm{~m}$ tidal amplitude starting $12.0 \mathrm{~km}$ offshore of the grounding line, and within $1 \mathrm{~mm}$ starting $17.3 \mathrm{~km}$ offshore. The slope of the deflection drops below $10^{-6}$ (compared with a maximum of $2.15 \times 10^{-4}$ ) starting $14.5 \mathrm{~km}$ offshore, and below $10^{-7}$ starting $20.2 \mathrm{~km}$ offshore. In observational studies, the hydrostatic line is often estimated as "where the gradient of each elevation curve [the displacement $w$ in our model] first tends to zero and is consistent with the tidal height predictions [our tidal forcing]" (Brunt et al., 2010); by this (partly visual) criterion, our hydrostatic line appears to be approximately $14 \mathrm{~km}$ offshore. This distance is somewhat long relative to observations of the Ross and Filchner-Ronne Ice Shelves by Brunt et al. (2010, 2011); the difference is likely due to the steepness of our shelf profile, and possibly also to the high resolution of model output relative to satellite measurements.

\subsection{Sensitivities}

For each of the experiments described below, all parameters and model inputs other than those explicitly mentioned remain at their values for the control experiment. Experiments in which the domain length is extended (maintaining constant ice thickness in the extensions) do not produce any change in the near-grounding line solution, indicating that the results of the control experiment are not influenced by boundary effects. We focus here primarily on changes in the flexure of grounded ice resulting from variation of model parameters.

Reducing Young's modulus to $3.0 \mathrm{GPa}$ and Poisson's ratio to zero (thus reducing the rigidity $D$ by over $47 \%$ ) results in slightly greater maximum deflection $( \pm 10.4 \mathrm{~mm})$ for the grounded ice, with a shortening of the area of nonzero deflection (maximum now only $500 \mathrm{~m}$ inland, and deflections greater than $1 \mathrm{~mm}$ only $1.7 \mathrm{~km}$ inland). Reducing the thickness of the grounded ice to $500 \mathrm{~m}$ decreases the rigidity by a factor of 8 , leading to similar but larger changes (maximum deflection of $\pm 11.7 \mathrm{~mm}$ at $400 \mathrm{~m}$ inland, deflection greater than $1 \mathrm{~mm}$ extending $1.2 \mathrm{~km}$ inland). These results are consistent with the general principle that response to an applied load becomes larger and more local as the rigidity of a beam decreases (e.g., Holdsworth, 1969). In contrast, changing to a linear shelf profile increases the rigidity of the lever while maintaining the rigidity of the grounded ice, resulting in the same area of nonzero deflection as the control experiment while increasing the maximum deflection to $\pm 11.8 \mathrm{~mm}$.

We find that reducing the viscosity significantly is not possible, as values below $3 \times 10^{14}$ Pa s cause the control experiment to become underdamped, with deflections growing over time. This underdamping is relatively weak for $v \sim 10^{14} \mathrm{~Pa}$, requiring several days for deflections to grow noticeably, but becomes stronger for $v \sim 10^{13} \mathrm{~Pa} \mathrm{~s}$, with deflections greater than the elastic solution appearing within the first tidal cycle. Increased viscosity shortens the delay in response relative to a purely elastic beam, with the solution for $v=10^{17}$ Pa s nearly indistinguishable from the elastic solution. We thus find that there is a relatively narrow range of values for which the viscosity significantly affects the model.

As expected, the deflection (both offshore and inland) is a linear function of the tidal amplitude. The inland deflection is also strongly (but nonlinearly) dependent on the spring constant. When $k$ is reduced by half, the maximum deflection increases to $\pm 14.2 \mathrm{~mm}$ at $700 \mathrm{~m}$ inland, with deflections greater than $1 \mathrm{~mm}$ extending up to $2.6 \mathrm{~km}$ inland. Doubling $k$ reduces the maximum deflection to $\pm 7.4 \mathrm{~mm}$ at $500 \mathrm{~m}$ inland, with deflections greater than $1 \mathrm{~mm}$ reaching only $1.6 \mathrm{~km}$ inland. The spring constant clearly plays an important role in limiting deflections to realistic values, as repeating the control experiment with $k=0$ (corresponding to the unphysical assumption that vertical motion of grounded ice has no effect on the pressure at its base) gives deflections greater than $2600 \mathrm{~mm}$ over $20 \mathrm{~km}$ inland.

We now consider whether our empirically chosen value for the spring constant $\left(k=5 \times 10^{6} \mathrm{~Pa} \mathrm{~m}^{-1}\right)$ is physically plausible. We begin with the case of till overlying bedrock. With Young's modulus for till ranging from 2 to $30 \mathrm{MPa}$ (C. Marone, unpublished data from experiments in Rathbun et al. (2008); c.f. Dorf, 2004), a typical layer thickness of a few meters leads to $10^{7} \mathrm{~Pa} \mathrm{~m}^{-1}$ as a reasonable value for $k$ in the till. Similarly, bedrock with Young's modulus of $O(10) \mathrm{GPa}$ and elastic response likely extending a few $\mathrm{km}$ deep (comparable to the flexural wavelength of the ice) leads to $k=10^{7} \mathrm{~Pa} \mathrm{~m}^{-1}$. The combined elastic response may be modeled as a compound spring consisting of two springs connected in series, so that each spring bears the full load. The spring constant is then given by $k=k_{1} k_{2} /\left(k_{1}+k_{2}\right)$ (e.g., Nautiyal, 2001), which in this case gives our chosen value of $k=5 \times 10^{6} \mathrm{~Pa} \mathrm{~m}^{-1}$. Considering reasonable values for both material properties and observed deflections suggests that $k$ should lie roughly in the range of $1 \times 10^{6}$ to $3 \times 10^{7} \mathrm{~Pa} \mathrm{~m}^{-1}$, corresponding to maximum deflections between 0.44 and $2.2 \mathrm{~cm}$ for our control experiment. We also consider the addition of a thin layer (a few $\mathrm{cm}$ ) of water, assuming for simplicity that the till is sufficiently saturated for this case to be modeled as a three-component compound spring. As the bulk modulus of water is over $2 \mathrm{GPa}$, the spring constant for this layer will be on the order of $10^{11} \mathrm{~Pa} \mathrm{~m}^{-1}$. This is so much stiffer than either the till or bedrock layer that its addition in series would have (for our purposes) negligible effect on the spring constant of the till-bedrock combination.

\section{Implications for subglacial hydrology}

Because we have an elastic foundation underlying the grounded ice, the change in subglacial pressure at any point on the ice stream is just $\Delta P=-k w$. (We thus implicitly assume that water, where present, is locally redistributed quickly enough to avoid formation of air-filled cavities; however, this does not yet allow extensive horizontal flow of water in response to the changing pressure.) Applying this to our control experiment, we see that the maximum pressure drop beneath grounded ice induced by low tide is $51.5 \mathrm{kPa}$, located $600 \mathrm{~m}$ inland at the point of maximum uplift; we note that an average density of $1028 \mathrm{~kg} \mathrm{~m}^{-3}$ for seawater gives a pressure drop of only $10.08 \mathrm{kPa}$ in the ocean when the tide falls by $1 \mathrm{~m}$. The pressure gradient beneath grounded ice for the control run at low tide, from the calculated distribution of uplift with spatially constant $k$ (Fig. 4), ranges from $200 \mathrm{~Pa} \mathrm{~m}^{-1}$ at the grounding line to $42 \mathrm{~Pa} \mathrm{~m}^{-1}$ in the opposite direction at $1.2 \mathrm{~km}$ inland.

To assess the significance of this pressure gradient, we compare it with typical (zero-flexure) values of the gradient of the subglacial hydraulic potential $\phi_{h}$ :

$\nabla \phi_{h}=\rho_{i} g \nabla S+\left(\rho_{w}-\rho_{i}\right) g \nabla B$,

where $S$ and $B$ are the surface and basal elevations of the ice stream (Shreve, 1972; Cuffey and Paterson, 2010). For ice streams similar to those on the Siple Coast, with surface slopes of $5 \times 10^{-3}$ or less, $\nabla \phi_{h}$ is generally below $50 \mathrm{~Pa} \mathrm{~m}^{-1}$; on near-groundingline ice plains, the hydraulic gradient can be much lower. We thus 


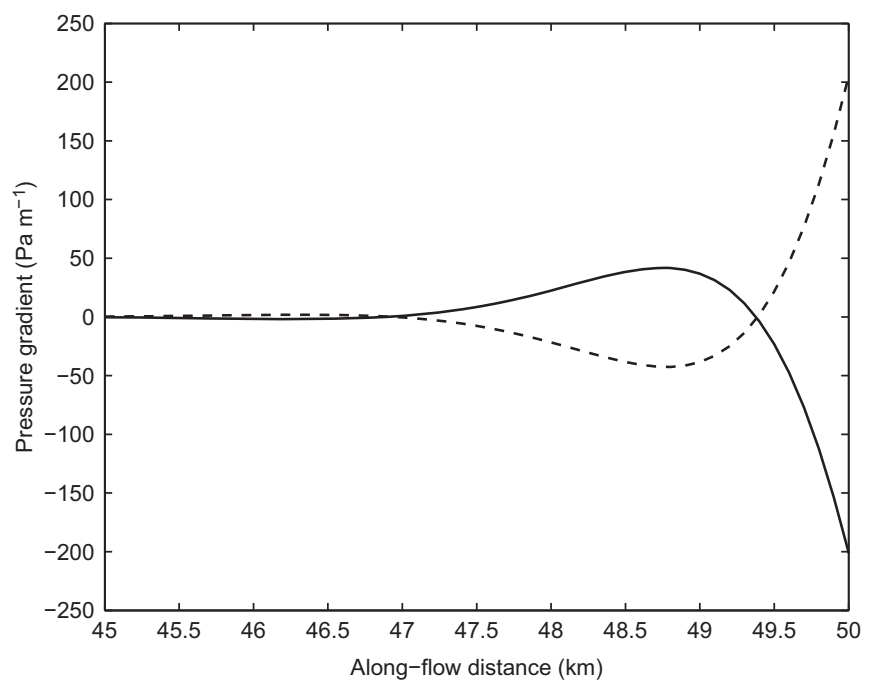

Fig. 4. Pressure gradient under grounded ice for control experiment at high (solid line) and low (dashed line) tide.

conclude that the pressure gradient caused by ice pressure could significantly influence subglacial water flow, although further investigation of the detailed structure of the water system is necessary to fully assess its effect. In particular, the relative sizes of the flexural pressure gradient and hydraulic gradient suggest the possibility of ocean water being drawn into the subglacial water system near low tide, with a brackish mixture being forced farther inland when the pressure gradient reverses near high tide.

The maximum pressure drop generated in the model is clearly dependent on the spring constant $k$. To investigate this sensitivity, we calculate the maximum pressure drop and corresponding uplift at low tide for a broad range of $k$ (Fig. 5). The nonlinear relationship between $k$ and $\max (w)$ leads to greater uplift for smaller pressure drops, which is consistent with interpreting the pressure drop as the self-weight that must be supported by the ice. For the model configuration used in the control experiment, the subglacial pressure drop exceeds the ocean pressure drop ( $10.08 \mathrm{kPa}$, as noted above) when the maximum uplift is less than $4 \mathrm{~cm}$; this difference becomes large as the maximum uplift falls toward the observed value of approximately $1 \mathrm{~cm}$. This suggests that ocean water being drawn beneath the ice stream is possible for a broad range of $k$, again pointing to a need for further investigation.

\section{Discussion}

Observational confirmation of inland flexure is difficult due to the low amplitude of the vertical displacement. Vertical changes of $1 \mathrm{~cm}$ cannot be reliably measured using satellite laser altimetry (Fricker et al., 2005) and are at the resolution limits of GPS on floating ice (King, 2004). Differential interferometric synthetic aperture radar is also unable to directly detect the inland flexure limit $F$ (Fig. 1); studies relying on this method (Rignot, 1998; Rignot et al., 2011) have calculated $F$ by fitting an elastic-beam model to observations. Other geophysical techniques, however, namely tiltmeters for surface observations and ice-penetrating radar (IPR) for basal observations, show more promise. Tiltmeters generally have sub-millimeter accuracy (Smith, 1991) and have been used to locate the limit of inland flexure along grounding lines in the Ross and Ronne-Filchner embayments (Smith, 1991; Jacobel and Bindschadler, 1994). Recent ground-based ice-penetrating radar observations along the grounding line of West

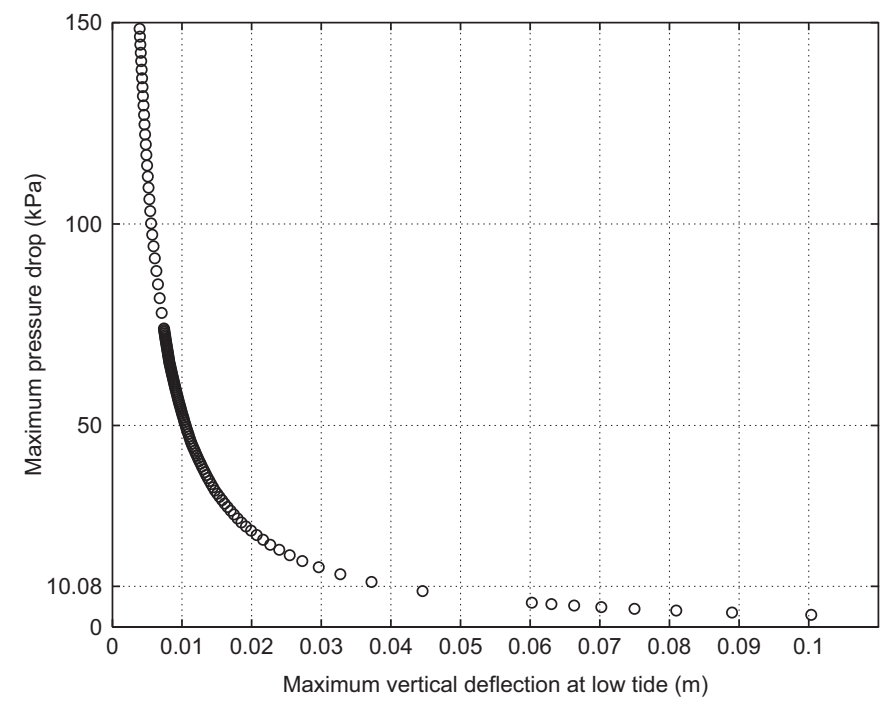

Fig. 5. Pressure drop as a function of maximum uplift of grounded ice at low tide. Note that $10.08 \mathrm{kPa}$ corresponds to the pressure drop in the ocean at a tidal height of $-1 \mathrm{~m}$. Except for the spring constant $k$, model parameters are as for the control experiment.

Antarctica's Siple Coast and East Antarctica's Dronning Maud Land, which rigorously account for spatial variation in englacial attenuation using direct measurements (MacGregor et al., 2011) or multiple models (Matsuoka et al., 2012), indicate that grounding lines, as depicted on ice-penetrating radar, are spatially variable. On the Siple Coast, lack of a change in amplitude of the basal reflector across the grounding line indicates that there may be a brackish layer of water well upstream ( $\sim 10 \mathrm{~km}$ of the grounding line) (MacGregor et al., 2011); in contrast, observations in Dronning Maud Land show a sharp contrast in basal reflectivity, indicating the grounding line here may be a barrier to seawater intrusion (Matsuoka et al., 2012). A complete investigation of large, existing airborne IPR datasets could indicate areas where seawater intrusion may occur inland of grounding lines and whether these areas are correlated with areas where tidal flexure may locally affect hydropotential enough to force seawater infiltration upstream of grounding lines. Access to the upstream and downstream parts of the grounding zone, by borehole and submersible, would be of great interest and may be required to gain full understanding.

The possibility of seawater intrusion strongly suggests that future work on near-grounding-line tidal flexure will require coupling a model of subglacial hydrology with a viscoelastic beam model. Even for the fairly large pressure gradients induced by ice flexure, it is unlikely that Darcian flow through the till (e.g., Murray and Clarke, 1995; Pimentel and Flowers, 2011) could transport enough water during a partial tidal cycle to greatly reduce the pressure gradient, given reasonable values of effective conductivity and layer thickness. This suggests that the flexure will affect hydrologic potential and thus flow in the subglacial water system, whether it consists of a sheet (Weertman, 1972), a network of shallow canals (Walder and Fowler, 1994), or cavities and channels in some combination (Schoof, 2010). In turn, this is likely to affect lubrication of ice flow, and sediment transport. Modeling this system will be complicated by the requirement that the water discharge to the ocean at the onset of flotation, rather than flowing at a water pressure slightly less than the ice overburden and controlled by local ice-watersediment interactions, as occurs well upstream of the grounding zone. Further complexity will be introduced by the effects of changing load and water pressure on till properties, and 
additional modeling may need to consider a fulcrum that moves during the tidal cycle. We anticipate that considerable modeling and observational work will be required to understand this system fully and model it accurately across the range of possible conditions.

If a significant fraction of the peak uplift of grounded ice at low tide is accommodated by lateral inflow of water, then both the pressure drop and the elastic deformation of the substrate there will be smaller than calculated above; however, the pressure drop must remain significant to drive the water inflow. Given the known wide range of hydrological systems beneath glacial ice (e.g, Walder and Fowler, 1994; Schoof, 2010; Pimentel and Flowers, 2011), diverse behavior at different grounding lines seems likely.

The tidal flexure of the downglacier part of the ice stream will load and unload any till beneath. A range of behaviors is possible, but with a general tendency for cyclic loading at such frequencies to favor net compaction (e.g., Murray and Clarke, 1995; Lekarp et al., 2000). If this proves to apply to an ice stream that is lubricated by a soft, deforming till, then the glacier bed in the region so affected will be relatively stiff, slowing the ice flow and stabilizing the grounding line. This is consistent with observations showing that the surface of the Siple Coast ice streams steps down relatively steeply in crossing a relatively stable groundingline position into the Ross Ice Shelf (Horgan and Anandakrishnan, 2006), and with the GPS and seismic evidence for a "sticky spot" acting near the grounding zone of one of these ice streams (Whillans) during its twice-daily events of rapid slip (Winberry et al., 2011). These are clear targets for additional field studies.

\section{Conclusions}

Physical understanding and the limited available data indicate that tidal flexure of ice-stream/ice-shelf systems should cause vertical displacements extending inland of the grounding line. Our viscoelastic flowline model, including elastic response of likely subglacial materials, produces vertical displacement of order $1 \mathrm{~cm}$ on the order of $1 \mathrm{~km}$ inland, consistent with available data. The associated subglacial pressure variations are larger than the tidal effect in the free ocean, with gradients along flow that reach peak values much larger than those farther inland driving subglacial water flow toward the grounding zone. We anticipate that additional modeling of the fully coupled system will show that the large, oscillating subglacial pressure gradients in and near the grounding zone exert important controls on the coupled flow of ice, water and till, perhaps including transport of seawater well inland. Further observations with ice-penetrating radar will be needed to locate areas of seawater intrusion beneath grounded ice and assess their effects on grounding-line detection by radar reflectivity.

\section{Acknowledgments}

All authors were supported by the Center for Remote Sensing of Ice Sheets (CReSIS) under NSF Grant 0424589. R.T.W. and B.R.P. were supported by NSF Grant 0909335 and NASA Grants NNX-09-AV94G and NNX-10-AI04G. B.R.P. was also supported by NSF Grant 0758274. We thank the editorial staff and two anonymous reviewers for their efforts.

\section{References}

Anandakrishnan, S., Catania, G.A., Alley, R.B., Horgan, H.J., 2007. Discovery of till deposition at the grounding line of Whillans Ice Stream. Science 315, 1835-1838, http://dx.doi.org/10.1126/science.1138393.
Anandakrishnan, S., Voigt, D.E., Alley, R.B., King, M.A., 2003. Ice stream D flow speed is strongly modulated by the tide beneath the Ross Ice Shelf. Geophys. Res. Lett. 30, 1361, http://dx.doi.org/10.1029/2002GL016329.

Bindschadler, R.A., King, M.A., Alley, R.B., Anandakrishnan, S., Padman, L., 2003. Tidally controlled stick-slip discharge of a West Antarctic ice stream. Science 301 (5636), 1087-1089.

Bindschadler, R., Choi, H., Wichlacz, A., Bingham, R., Bohlander, J., Brunt, K., Corr, H., Drews, R., Fricker, H., Hall, M., Hindmarsh, R., Kohler, J., Padman, L., Rack, W., Rotschky, G., Urbini, S., Vornberger, P., Young, N., 2011. Getting around Antarctica: new high-resolution mappings of the grounded and freelyfloating boundaries of the Antarctic ice sheet created for the International Polar Year. Cryos. 5, 569-588, http://dx.doi.org/10.5194/tc-5-569-2011.

Brunt, K.M., Fricker, H.A., Padman, L., Scambos, T.A., O'Neel, S., 2010. Mapping the grounding zone of the Ross Ice Shelf, Antarctica, using ICESat laser altimetry. Ann. Glaciol. 51, 71-79.

Brunt, K.M., Fricker, H.A., Padman, L., 2011. Analysis of ice plains of the FilchnerRonne Ice Shelf, Antarctica, using ICESat laser altimetry. J. Glaciol. 57, 965-975.

Cuffey, K.M., Paterson, W.S.B., 2010. The Physics of Glaciers, 4th ed. Elsevier.

Dorf, R.C., 2004. CRC Handbook of Engineering Tables. CRC Press.

Fricker, H.A., Borsa, A., Minster, B., Carabajal, C., Quinn, K., Bills, B., 2005. Assessment of ICESat performance at the Salar de Uyuni, Bolivia. Geophys. Res. Lett. 32, L21S06, http://dx.doi.org/10.1029/2005GL023423.

Fricker, H.A., Coleman, R., Padman, L., Scambos, T.A., Bohlander, J., Brunt, K.M., 2009. Mapping the grounding zone of the Amery Ice Shelf, East Antarctica using InSAR, MODIS and ICESat. Antarct. Sci. 21 (5), 515-532.

Gudmundsson, G.H., 2007. Tides and the flow of Rutford Ice Stream, West Antarctica. J. Geophys. Res. 112, F04007, http://dx.doi.org/10.1029/ 2006JF000731.

Gudmundsson, G.H., 2011. Ice-stream response to ocean tides and the form of the basal sliding law. Cryos. 5, 259-270, http://dx.doi.org/10.5194/tc-5-259-2011.

Heinert, M., Riedel, B., 2007. Parametric modelling of the geometrical ice-ocean interaction in the Ekstroemisen grounding zone based on short time-series. Geophys. J. Int. 169, 407-420.

Hibbeler, R.C., 2000. Mechanics of Materials, 4th ed. Prentice Hall.

Holdsworth, G., 1969. Flexure of a floating ice tongue. J. Glaciol. 8, 385-397.

Holdsworth, G., 1977. Tidal interaction with ice shelves. Ann. Geophys. 33, 133-146.

Holland, P.R., Jenkins, A., Holland, D.M., 2008. The response of ice shelf basal melting to variations in ocean temperature. J. Clim. 21, 2258-2572.

Horgan, H.J., Anandakrishnan, S., 2006. Static grounding lines and dynamic ice streams: evidence from the Siple Coast, West Antarctica. Geophys. Res. Lett. 33 (18), L18502, http://dx.doi.org/10.1029/2006GL027091.

Jacobel, R.W., Bindschadler, R.A., 1994. Studies of the grounding line location on Ice Streams D and E, Antarctica. Ann. Glaciol. 20, 39-42.

Jones, G., 1997. Analysis of Beams on Elastic Foundations, Telford.

King, M., 2004. Rigorous GPS data-processing strategies for glaciological applications. J. Glaciol. 50 (171), 601-607.

King, M.A., Murray, T., Smith, A.M., 2010. Non-linear responses of Rutford Ice Stream, Antarctica, to semi-diurnal and diurnal tidal forcing. J. Glaciol. 56, 167-176.

Lekarp, F., Isacsson, U., Dawson, A., 2000. State of the art II: permanent strain response of unbound aggregates. J. Transp. Eng. 126 (1), 76-83, http://dx.doi.o $\mathrm{rg} / 10.1061 /($ ASCE)0733-947X(2000)126:1(76).

Lingle, C.S., Hughes, T.J., Kollmeyer, R.C., 1981. Tidal flexure of Jakobshavns Glacier, West Greenland. J. Geophys. Res. 86, 3960-3968.

MacGregor, J.A., Anandakrishnan, S., Catania, G., Winebrenner, D.P., 2011. The grounding zone of the Ross Ice Shelf, West Antarctica, from icepenetrating radar. J. Glaciol. 57 (205), 917-928, http://dx.doi.org/10.3189/ 02214311798043780.

Matsuoka, K., Pattyn, F., Callens, D., Conway, H., 2012. Radar characterization of the basal interface across the grounding zone of an ice-rise promontory in East Antarctica. Ann. Glaciol. 53 (60), 29-34, http://dx.doi.org/10.3189/ 2012AoG60A106.

Murray, T., Clarke, G.K.C., 1995. Black-box modeling of the subglacial water system. J. Geophys. Res. 100 (B7), 10231-10245.

Murray, T., Smith, A.M., King, M.A., Weedon, G.P., 2007. Ice flow modulated by tides at up to annual periods at Rutford Ice Stream, West Antarctica. Geophys. Res. Lett. 34 (18), L18503, http://dx.doi.org/10.1029/2007GL031207.

Nautiyal, B.D., 2001. Introduction to Structural Analysis. New Age International.

Pimentel, S., Flowers, G.E., 2011. A numerical study of hydrologically driven glacier dynamics and subglacial flooding. Proc. R. Soc. Lond. Ser. A 467, 537-558.

Rathbun, A.P., Marone, C., Alley, R.B., Anandakrishnan, S., 2008. Laboratory study of the frictional rheology of sheared till. J. Geophys. Res. 113, F02020 http://dx.doi.org/10.1029/2007JF000815.

Reeh, N., Christensen, E.L., Mayer, C., Olesen, O.B., 2003. Tidal bending of glaciers: a linear viscoelastic approach. Ann. Glaciol. 37, 83-89.

Rignot, E., 1998. Hinge-line migration of Petermann Gletscher, north Greenland, detected using satellite-radar interferometry. J. Glaciol. 44 (148), 469-476.

Rignot, E., Mouginot, J., Scheuchl, B., 2011. Antarctic grounding line mapping from differential satellite radar interferometry. Geophys. Res. Lett. 38, L10504, http://dx.doi.org/10.1029/2011GL047109.

Robin, G.de.Q., 1958. Glaciology III, Seismic shooting and related investigations. In: Norwegian-British-Swedish Antarctic Expedition, 1949-1952, Scientific Results, vol. V, Norsk Polarinstitut.

Sayag, R., Worster, M.G., 2011. Elastic response of a grounded ice sheet coupled to a floating ice shelf. Phys. Rev. E 84, 036111, http://dx.doi.org/10.1103/ PhysRevE.84.036111. 
Scambos, T.A., Haran, T.M., Fahnestock, M.A., Painter, T.H., Bohlander, J., 2007. MODIS-based Mosaic of Antarctica (MOA) data sets: continent-wide surface morphology and snow grain size. Remote Sensing Environ. 111 (2-3) 242-257, http://dx.doi.org/10.1016/j.rse.2006.12.020.

Schmeltz, M., Rignot, E., MacAyeal, D., 2002. Tidal flexure along ice-sheet margins: comparison of InSAR with an elastic-plate model. Ann. Glaciol. 34, 202-208.

Schoof, C., 2010. Ice-sheet acceleration driven by melt supply variability. Nature 468, 803-806.

Shreve, R.L., 1972. Movement of water in glaciers. J. Glaciol. 11 (62), 205-214.

Smith, A.M., 1991. The use of tiltmeters to study the dynamics of Antarctic iceshelf grounding lines. J. Glaciol. 37, 51-58.

Turcotte, D.L., Schubert, G., 2002. Geodynamics, 2nd ed. Cambridge.

Vaughan, D.G., 1995. Tidal flexure at ice shelf margins. J. Geophys. Res. 100 (B4), 6213-6224.

Walder, J.S., Fowler, A., 1994. Channelized subglacial drainage over a deformable bed. J. Glaciol. 40 (134), 3-15.
Walter, J.I., Brodsky, E.E., Tulaczyk, S., Schwartz, S.Y., Pettersson, R., 2011. Transient slip events from near-field seismic and geodetic data on a glacier fault, Whillans Ice Plain, West Antarctica. J. Geophys. Res. 116, F01021, http: //dx.doi.org/10.1029/2010JF001754.

Weertman, J., 1972. General theory of water flow at the base of a glacier or ice sheet. Rev. Geophys. Space Phys. 10, 287-333.

Winberry, J.P., Anandakrishnan, S., Alley, R.B., Bindschadler, R.A., King, M.A., 2009. Basal mechanics of ice streams: insights from the stick-slip motion of Whillans Ice Stream, West Antarctica. J. Geophys. Res. 114, F01016, http://dx.doi.org/ 10.1029/2008JF001035.

Winberry, J.P., Anandakrishnan, S., Wiens, D.A., Alley, R.B., Christianson, K., 2011 Dynamics of stick-slip motion, Whillans Ice Stream, Antarctica. Earth Planet. Sci. Lett. 305, 283-289, http://dx.doi.org/10.1016/j.epsl.2011.02.052. 